\title{
Lamin A/C augments Th1 differentiation and response against vaccinia virus and Leishmania major
}

\author{
Raquel Toribio-Fernández', Virginia Zorita', Vera Rocha-Perugini ',2, Salvador Iborra', Gloria Martínez del Hoyo', \\ Raphael Chevre ${ }^{1}$, Beatriz Dorado ${ }^{1}$, David Sancho ${ }^{1}$, Francisco Sanchez-Madrid ${ }^{1,2,3}$, Vicente Andrés ${ }^{1,3}$ and \\ Jose-Maria Gonzalez-Granado 1,3,4
}

\begin{abstract}
Differentiation of naive CD4 ${ }^{+}$T-cells into functionally distinct $T$ helper (Th) subsets is critical to immunity against pathogen infection. Little is known about the role of signals emanating from the nuclear envelope for T-cell differentiation. The nuclear envelope protein lamin $\mathrm{A} / \mathrm{C}$ is induced in naive $\mathrm{CD} 4^{+} \mathrm{T}$-cells upon antigen recognition and acts as a link between the nucleus and the plasma membrane during T-cell activation. Here we demonstrate that the absence of lamin A/C in naive T-cell reduces Th1 differentiation without affecting Th2 differentiation in vitro and in vivo. Moreover, Rag $1^{-1}$ mice reconstituted with $\mathrm{Lmna}^{-/-} \mathrm{CD} 4^{+} \mathrm{CD} 25^{-} \mathrm{T}$-cells and infected with vaccinia virus show weaker Th1 responses and viral removal than mice reconstituted with wild-type T-cells. Th1 responses and pathogen clearance upon Leishmania major infection were similarly diminished in mice lacking lamin $A / C$ in the complete immune system or selectively in T-cells. Lamin A/C mediates Th1 polarization by a mechanism involving T-bet and IFNy production. Our results reveal a novel role for lamin A/C as key regulator of Th1 differentiation in response to viral and intracellular parasite infections.
\end{abstract}

\section{Introduction}

The nuclear envelope is composed of nuclear pore complexes, the outer and inner nuclear membranes, and the nuclear lamina. The nuclear lamina is a filamentous protein layer mainly composed of A- and B-type lamins and provide mechanical stability to the inner nuclear membrane, regulating nucleus positioning, chromatin structure, nuclear pore complex organization, nuclear envelope breakdown and reassembly during mitosis, DNA replication, DNA damage responses, cell-cycle progression, cell differentiation, cell polarization during cell migration, and transcription ${ }^{1,2}$. We have previously shown that lamin A expression is triggered in naive $\mathrm{T}$ -

Correspondence: J-M. Gonzalez-Granado (jmgonzalezgranado@gmail.com) ${ }^{1}$ Centro Nacional de Investigaciones Cardiovasculares Carlos III (CNIC), Madrid, Spain

${ }^{2}$ Servicio de Inmunología, Hospital de la Princesa, Instituto de Investigación Sanitaria La Princesa (IIS Princesa), Madrid, Spain

Full list of author information is available at the end of the article cells upon antigen recognition and enhances T-cell activation by coupling actin dynamics and immunological synapse formation ${ }^{3}$.

T-cells orchestrate the protection against microbial pathogens ${ }^{4}$. In peripheral lymphoid organs, antigenpresenting cells (APCs) stimulate cognate $\mathrm{CD} 4^{+} \mathrm{T}$-cells, which proliferate and undergo differentiation into distinct specialized effector $\mathrm{T}$ helper (Th) cells that are essential for the development of adaptive immune responses ${ }^{5}$. Tight control of naive T-cell differentiation is crucial for eliciting an appropriate host defense, triggering immunemediated inflammation without deleterious tissue damage. Th subsets are defined by the differential expression of surface markers, transcription factors, and effector cytokines and play essential and distinct roles in mediating or directing the nature of the response to pathogens, commensals, and vaccines. T-cell differentiation in diverse Th subsets depends on the type of antigen encountered, the TCR signal intensity, and the local 
cytokine milieu ${ }^{4,6-8}$. Indeed, Th1 differentiation, which is required for host defense against intracellular pathogens, involves interferon- $\gamma$ (IFN $\gamma$ ) production in an interleukin (IL)-2-dependent manner by the transcription factor Tbet $^{6}$. Th2 differentiation is triggered by extracellular pathogens or allergens through the induction of GATA-3 and the activation of IL-4-dependent signal transducer and activator of transcription factor 6 (Stat-6) ${ }^{9}$. Signals emanating from the nuclear interior may also condition naive T-cell polarization. Here we show that lamin A/C expression augments $\mathrm{CD} 4^{+} \mathrm{T}$-cell Th1 differentiation in response to pathogen infection by regulating T-bet transcription factor expression and IFN $\gamma$ production.

\section{Results}

\section{Lamin A/C regulates Th1 differentiation}

To analyze the role of A-type lamins in antigendependent T-cell differentiation, $L m n a^{-/-}$and wild-type (WT) mice were back-crossed with OTII mice, which express a TCR (T-cell receptor) specific for ovalbumin (OVA) peptide. Naive $\mathrm{CD} 4^{+} \mathrm{T}$-cells were isolated from Lmna ${ }^{-/-}$/OTII or WT/OTII mice and co-cultured with OVA-loaded WT APCs in the absence of polarizing cytokines. Compared with WT $\mathrm{CD}^{+}$T-cells, fewer Lmna $^{-/-} \mathrm{CD} 4^{+}$T-cells were IFN $\gamma^{+}$, indicating the importance of lamin $\mathrm{A} / \mathrm{C}$ for antigen-dependent Th1 differentiation (Fig. 1a). This difference was not abolished by addition of IL-2 (Fig. 1b). We next directed Th1 or Th2 differentiation in vitro by incubating WT and $L m n a^{-/-}$ $\mathrm{CD}_{4}{ }^{+}$T-cells with anti-CD3 and anti-CD28 antibodies and Th1 or Th2 polarizing cytokines. Interestingly, Lmna $^{-/-} \mathrm{CD} 4^{+} \mathrm{T}$-cells produced fewer Th1 cells than WT cells but similar numbers of Th2 cells (Fig. 1c). Th1 differentiation triggered by co-culture with OVA-loaded WT APCs in the presence of Th1 polarizing cytokines was also lower in $\mathrm{CD} 4^{+}$T-cells from $\mathrm{Lmna}^{-/-}$/OTII mice than in WT/OTII T-cells (Fig. 1d). These experiments suggest that lamin $\mathrm{A} / \mathrm{C}$ is an important intrinsic regulator of T-cell differentiation following TCR stimulation.

\section{Lamin A/C enhances Th1 responses in vivo}

It has been previously shown that intrinsic lamin A/C does not affect $\mathrm{T}$-cell development ${ }^{10}$. Moreover, we did not observe any role for lamin $\mathrm{A} / \mathrm{C}$ in very early $\mathrm{T}$-cell activation. Indeed, TCR stimulation triggered similar levels of extracellular signal-regulated kinase $1 / 2$ (ERK1/2) phosphorylation in WT and Lmna ${ }^{-/-}$CD4 T-cells (Figure $\mathrm{S} 1 \mathrm{a}$, day 0 ), indicating that lamin $\mathrm{A} / \mathrm{C}$ is not involved in T-cell development and early TCR activation. We have previously shown that lamin $\mathrm{A} / \mathrm{C}$ is transiently expressed in $\mathrm{CD}^{+}{ }^{+} \mathrm{T}$-cells upon antigen recognition ${ }^{3}$. Confirming our previous observation, levels of pERK $1 / 2$ were increased in WT lamin A/C-expressing cells but not in Lmna $^{-/-}$CD4 T-cells after a second TCR stimulation, when lamin A/C is already expressed in WT CD4 T-cells (ref. 3; and Figure S1b), (Figure S1a, day 1).

To investigate the role of lamin $\mathrm{A} / \mathrm{C}$ in Th1 differentiation in vivo, mice were infected with vaccinia virus (VACV), which provokes a robust Th1 immune response in mice ${ }^{11,12}$. VACV infection induces transient expression of lamin $\mathrm{A} / \mathrm{C}$, peaking at 1 day after infection in draining lymph nodes (Figure S2). At 3 days after intraperitoneal VACV infection, the frequency of IFN $\gamma^{+} \mathrm{CD} 4^{+} \mathrm{T}$-cells in mesenteric lymph nodes and peritoneal exudate was lower in $\mathrm{Lmna}^{-1-}$ mice than in WT mice (Fig. 2a, b). To study the role of lamin $\mathrm{A} / \mathrm{C}$ specifically in the immune system, we reconstituted lethally irradiated WT CD45.1 mice with WT or $L_{m n a}{ }^{-1-}$ CD45.2 bone marrow for 2 months. Confirmation of bone marrow reconstitution with anti CD45.1 and CD45.2 antibodies revealed no significant differences between genotypes. After intraperitoneal infection with VACV, we analyzed the frequency of $\mathrm{IFN}^{+}$and $\mathrm{IL}_{-} 4^{+}$in $\mathrm{CD} 4^{+}$T-cells. Lmna $^{-\prime}$ ${ }^{-}$-reconstituted mice had proportionately fewer IFN $\gamma^{+} \mathrm{T}$ cells, and similar numbers of IL4 ${ }^{+}$T-cells with respect to WT-reconstituted mice, in both spleen and peritoneal exudate (Fig. 2c). To trigger antigen-specific Th1 responses in vivo, we reconstituted WT mice with either WT/OTII or Lmna ${ }^{-1-}$ /OTII bone marrow and then infected the mice intraperitoneally with VACV-OVA. As before, the $\mathrm{Lmna}^{-/} / \mathrm{OTII}$-reconstituted $\mathrm{CD} 4^{+}$population included a lower proportion of IFN $\gamma^{+}$cells than did WT/OTII-derived $\mathrm{CD}^{+}$cells (Fig. 2d). Moreover, reconstitution with a mix of bone marrow from WT/OTII and $L m n a^{-1-}$ /OTII mice produced a lower percentage of IFN $\gamma^{+} \mathrm{CD}^{+}{ }^{+}$T-cells in $\mathrm{Lmna}^{-/-} / \mathrm{OTII}$ than in WT/OTII cells (Fig. 2e). Our results indicate that lamin A/C depletion in the hematopoietic compartment impairs Th1 differentiation in vitro and in vivo. To directly assess the importance for Th1 differentiation of lamin $\mathrm{A} / \mathrm{C}$ in $\mathrm{CD} 4^{+}$ $\mathrm{T}$-cells, we adoptively transferred WT mice with $\mathrm{CD} 4^{+} \mathrm{T}$ cells from WT/OTII or Lmna ${ }^{-/-}$/OTII mice. Th1 differentiation from $\mathrm{Lmna}^{-/-} \mathrm{CD} 4^{+}$T-cells was weaker than from their WT counterparts, producing a lower percentage of IFN $\gamma^{+} \mathrm{CD} 4^{+}$T-cells (Fig. 3a). Similar results were obtained when WT recipient mice were transferred with a mix of WT/OTII and Lmna ${ }^{-/-} / \mathrm{OTII} C D 4^{+}$T-cells followed by VACV-OVA inoculation, either intraperitoneally (Fig. 3b) or subcutaneously in the footpad (Fig. 3c). These results indicate that lamin A/C expression specifically regulates $\mathrm{CD} 4^{+} \mathrm{T}$-cell differentiation toward Th1 cells in vivo.

We next investigated whether the action of lamin A/C in $\mathrm{CD}^{+}{ }^{+} \mathrm{T}$-cell polarization was related to antigen presentation by dendritic cells (DC). WT mice received subcutaneous injections of lipopolysaccharide (LPS)matured OVA-loaded bone marrow-derived DCs (BMDCs), which trigger Th1 differentiation ${ }^{13}$, and $18 \mathrm{~h}$ 


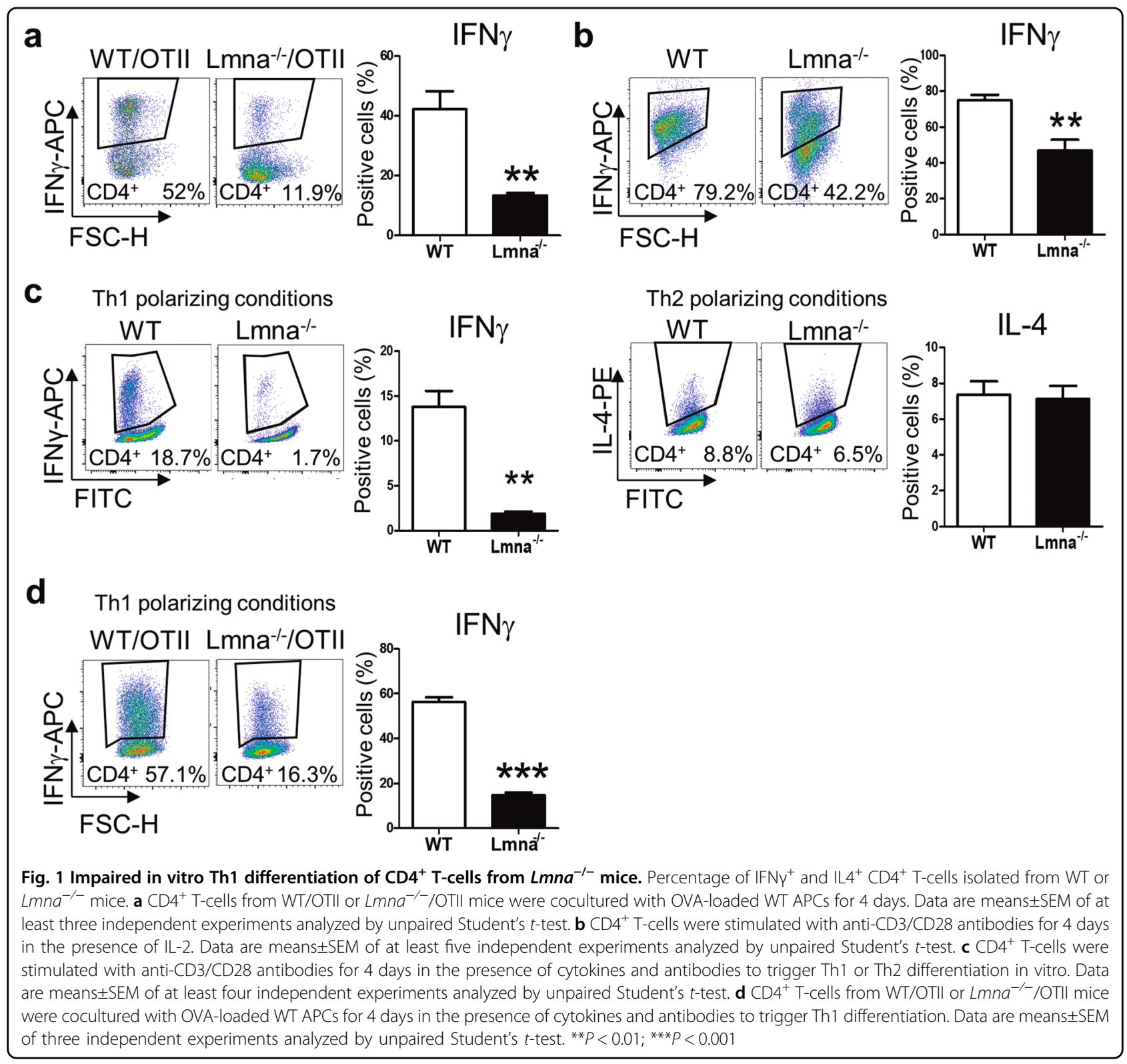

later received intravenous injections of WT/OTII or Lmna ${ }^{-/-} / \mathrm{OTII}$ CD4 ${ }^{+}$T-cells. After 7 days, Th1 differentiation of adoptively transferred $\mathrm{T}$-cells was analyzed in draining lymph nodes. Lmna ${ }^{-1-} / \mathrm{OTII} \mathrm{CD}^{+}$T-cells produced fewer IFN $\gamma^{+} \mathrm{CD} 4^{+}$T-cells in the presence of LPS-treated BMDCs than WT/OTII cells (Fig. 3d). In other experiments, WT mice received subcutaneous injections of splenic CD11 ${ }^{+}$DCs incubated $4 \mathrm{~h}$ in medium containing LPS or papain to potentiate antigendependent T-cell differentiation to Th1 or Th2, respectively $^{13,14}$. As before, $18 \mathrm{~h}$ later the mice received intravenous injections of WT/OTII or $\mathrm{Lmna}^{-/-}$/OTII $\mathrm{CD}^{+}{ }^{+} \mathrm{T}$-cells, and Th1 and Th2 differentiation was analyzed in draining lymph nodes after 7 days. Lmna $^{-1-}$ $\mathrm{CD}^{+}{ }^{+} \mathrm{T}$-cells produced fewer IFN $\gamma^{+} \mathrm{CD} 4^{+} \mathrm{T}$-cells in the presence of LPS-treated BMDCs than their WT counterparts; in contrast, in the presence of papain-treated BMDCs the proportion of IL $4^{+}$cells was similar in WT and Lmna $^{-/-} \mathrm{CD}^{+}$T-cells (Fig. 3e). These results indicate that lamin $\mathrm{A} / \mathrm{C}$ expression specifically regulates $\mathrm{CD} 4^{+} \mathrm{T}$-cell differentiation toward Th1 cells in vivo.

\section{Lamin $A / C$ enhances T-cell activation but is not essential for T-cell proliferation}

Reduced Th1 cell polarization from $L m n a^{-/-} \mathrm{CD}^{+} \mathrm{T}$ cells could be due to impaired T-cell activation, which is enhanced by lamin $\mathrm{A}$ in vitro ${ }^{3}$. We therefore analyzed $\mathrm{CD} 4^{+} \mathrm{T}$-cell activation in response to VACV infection in the absence of lamin A/C expression. A 1:1 mix of naive $\mathrm{CD}^{+}$T-cells from $\mathrm{Lmna}^{-/-} / \mathrm{OTII}$ and WT/OTII mice 
a

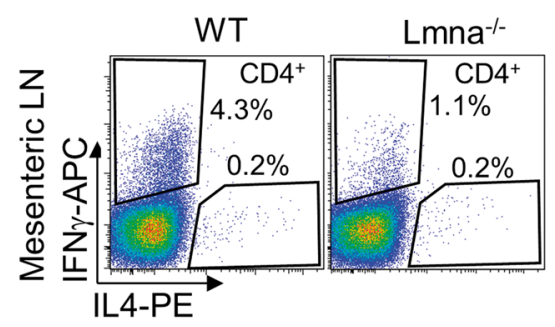

b

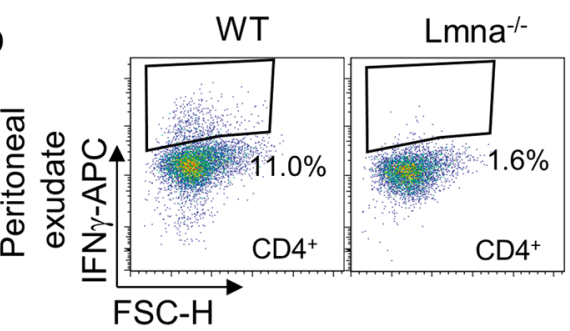

C
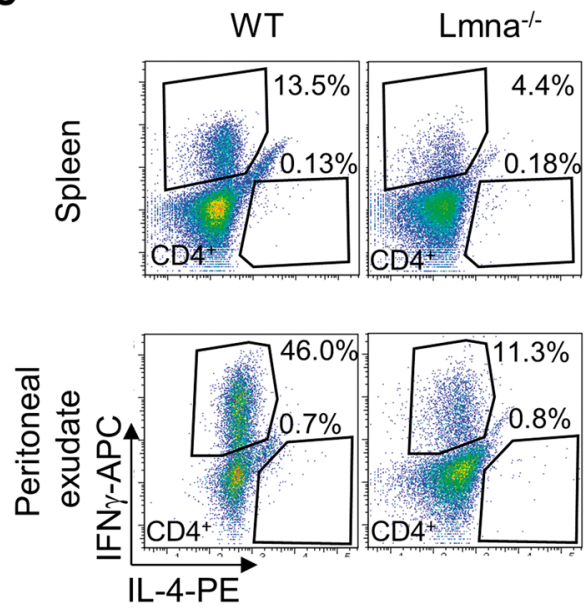

d

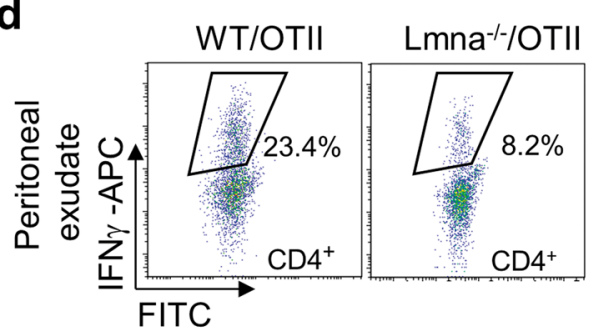

e

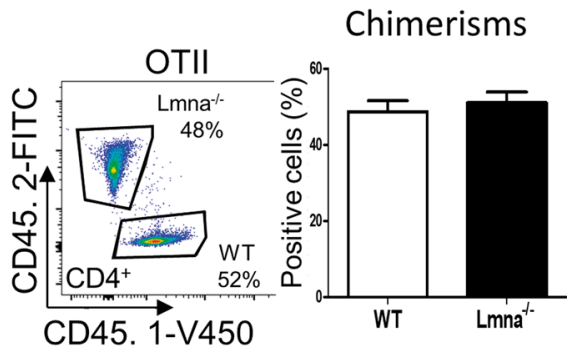

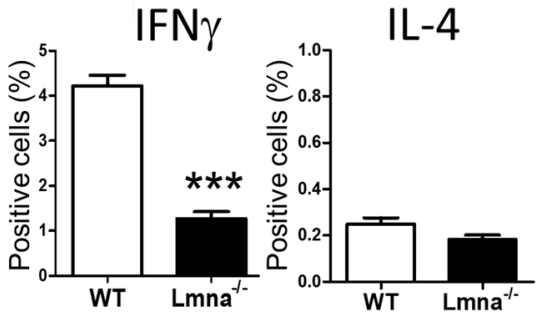

IFN $\gamma$
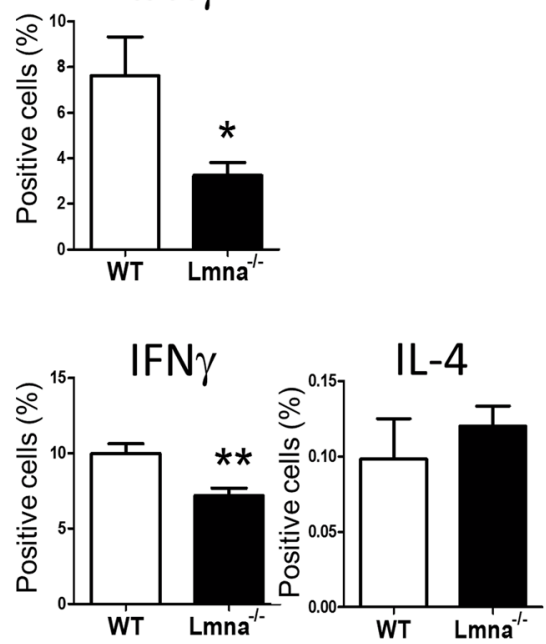

IFN $\gamma$

IL-4

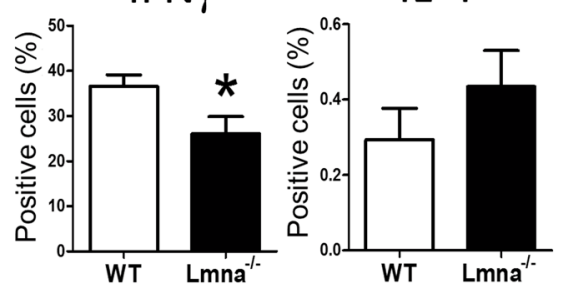

IFN $\gamma$

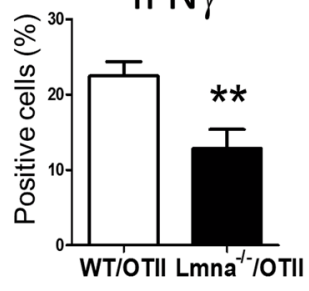

Popliteal LN

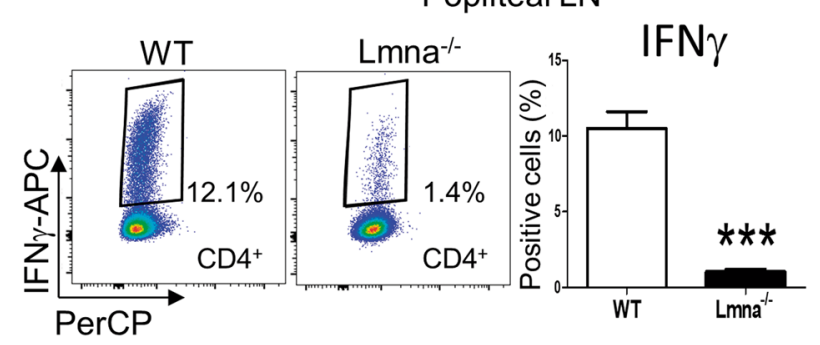

Fig. 2 (See legend on next page.) 
was adoptively transferred into WT recipient mice before intradermal infection with VACV-OVA. Surface expression of the T-cell activation markers CD25 and CD69 was measured $48 \mathrm{~h}$ later (Fig. 4a, b). Accordingly, compared with WT cells, $\mathrm{Lmna}^{-1-} \mathrm{CD} 4^{+} \mathrm{T}$-cells in draining lymph nodes expressed less CD25 and CD69.

Next, we investigated whether lamin A/C could regulate $\mathrm{T}$-cell proliferation, which occurs after antigen recognition and activation. However, proliferation after in vitro activation with anti-CD3 and anti-CD28 was similar in Lmna $^{-1-}$ and WT CD4 ${ }^{+}$T-cells (Fig. 4c). Similarly, after VACV infection, WT and $L m n a^{-1-}$ mice had similar levels of proliferating $\mathrm{CD} 4^{+} \mathrm{T}$-cells, as shown by Ki67 expression (Fig. 4d), proliferating cell nuclear antigen (PCNA) expression (Fig. 4e), and 5-bromo-2deoxyuridine (BrdU) incorporation (Fig. 4f-g). These experiments show that A-type lamins regulate T-cell activation without affecting cell proliferation.

\section{Lamin A/C enhances T-bet levels}

The master regulator of Th1 differentiation is T-bet. Analysis of T-bet expression in $\mathrm{CD}^{+}{ }^{-} \mathrm{T}$-cells revealed that deficiency in A-type lamins reduced both the percentage of $\mathrm{T}^{- \text {bet }^{+}}{ }^{+}$cells and $\mathrm{T}$-bet expression levels in anti-CD3/CD28-stimulated CD4 ${ }^{+}$T-cells (Fig. 5a, b). In agreement with the effect on Th1 differentiation, lamin A/ $\mathrm{C}$ deficiency also diminished the percentage of IFN $\gamma^{+} \mathrm{CD}^{+}$T-cells (Fig. 5a). Similar results were obtained after stimulation with anti-CD3/CD28 antibodies in the presence of Th1-differentiation cytokines (Fig. 5c). Moreover, lamin $\mathrm{A} / \mathrm{C}$ expression was also important for T-bet expression in vivo after Th1 differentiation triggered by VACV infection (Fig. 5d). Low Tbet protein expression in $\mathrm{Lmna}^{-1-} \mathrm{T}$-cells was accompanied by lower mRNA expression in vitro (Fig. 5e), suggesting regulation at the level of mRNA synthesis.

A-type lamins regulate TCR clustering and subsequent downstream signaling upon T-cell activation ${ }^{3}$. However, altered Th1 differentiation in the absence of lamin $\mathrm{A} / \mathrm{C}$ was not exclusively related to differences in TCR clustering, since the percentage of IFN $\gamma^{+}$and T-bet ${ }^{+}$Lmna $^{-\prime}$ - $\mathrm{CD}^{+}{ }^{+} \mathrm{T}$-cells was also lower after TCR-independent T- cell stimulation with phorbol myristate acetate (PMA) and ionomycin (Fig. 5a).

\section{Lamin $A / C$ regulates Th1 immunity against pathogen infection}

$\mathrm{T}$-bet and IFN $\gamma$ play major roles during in vivo Th1 responses against pathogens ${ }^{11,15,16}$. The low expression of these factors in $\mathrm{Lmna}^{-/-} \mathrm{CD} 4^{+} \mathrm{T}$-cells prompted us to investigate the role of lamin $\mathrm{A} / \mathrm{C}$ in Th1-mediated pathogen clearance in vivo. $\operatorname{Rag} 1^{-/-}$mice lacking $\mathrm{T}$ - and B-cells were adoptively transferred with naive $\mathrm{CD}^{-} \mathrm{CD}^{+}{ }^{+} \mathrm{T}$-cells from WT or $\mathrm{Lmna}^{-/-}$mice. Mice were infected with VACV by tail scarification. Without $\mathrm{CD}^{+}{ }^{+} \mathrm{T}$-cell adoptive transfer, $100 \%$ of $\mathrm{Rag} 1^{-/-}$mice die 12 days after VACV infection; $\mathrm{CD}^{+} \mathrm{T}$-cell adoptive transfer extends lifespan by accelerating viral clearance at least in part through a mechanism mediated by Th1 cells ${ }^{17}$. In our experiments, $\operatorname{Rag} 1^{-/-}$mice adoptively transferred with CD25 CD4 ${ }^{+}$Lmna $^{-/-}$T-cells were more susceptible to primary VACV infection, as indicated by an elevated viral titer and a reduced Th1 response in the spleen (Fig. 6a, b). Moreover, IFN $\gamma$ and T-bet mRNA expression was reduced in adoptively transferred mice, whereas the Th2 transcription factor GATA3 was unaffected (Fig. 6c). Viral clearance requires the efficient coordination of multiple immune effector mechanisms ${ }^{11}$. The role of lamin $\mathrm{A} / \mathrm{C}$ in viral clearance seems to be $\mathrm{CD}^{+}{ }^{+} \mathrm{T}$-cell dependent, since only $\mathrm{CD} 4^{+} \mathrm{T}$-cells were adoptively transferred to $\mathrm{Rag}^{-1-}$ mice before VACV infection. Effector $\mathrm{CD}^{+}{ }^{+} \mathrm{T}$-cells have been shown to respond to viral pathogens through two mechanisms: cytokine production (mostly IFN $\gamma$ and tumor necrosis factor- $\alpha(\mathrm{TNF} \alpha)$ ) and a direct cytolytic activity mediated by perforin and FAS (also known as CD95) ${ }^{11}$. CD4 ${ }^{+} \mathrm{T}$-cell cytotoxic activity does not require Th1 cell polarization but is dependent on the expression of the transcription factors T-bet, eomesodermin (Eomes), and Blimp-1, which are crucial for their development in vivo through the induction of granzyme $\mathrm{B}(\mathrm{GzmB})$ and perforin 1 $(\text { Prf1 })^{18,19}$. Interestingly, Rag1 $1^{-/-}$mice adoptively transferred with $\mathrm{Lmna}^{-1-} \mathrm{CD} 4^{+}$T-cells and scarified with VACV had lower levels of IFN $\gamma$ mRNA in the large

\footnotetext{
(see figure on previous page)

Fig. 2 Impaired in vivo Th1 differentiation of naive $\mathrm{CD}^{+}{ }^{+}$T-cells from $\mathrm{Lmna}^{-/-}$mice. Percentage of IFNY ${ }^{+}$or IL4 ${ }^{+} \mathrm{CD} 4^{+} \mathrm{T}$-cells upon VACV infection. $\mathbf{a}, \mathbf{b}$ WT and $\mathrm{Lmna}^{-/-}$mice were intraperitoneally infected with $\mathrm{VACV}$, and after 3 days mesenteric lymph nodes $\mathbf{a}$ and peritoneal exudate $\mathbf{b}$ were analyzed, $\left(n=11 \mathrm{WT}\right.$ and $7 \mathrm{Lmna}^{-/-}$mice). Data are means \pm SEM analyzed by unpaired Student's $t$-test. c Irradiated CD $45.1^{+}$WT mice were

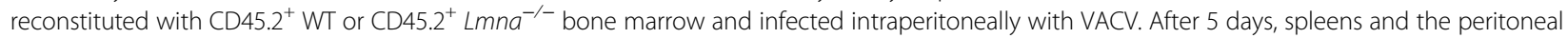
exudate were analyzed by flow cytometry ( $n=7$ and 8-11 mice from two independent experiments). Data are means \pm SEM analyzed by unpaired

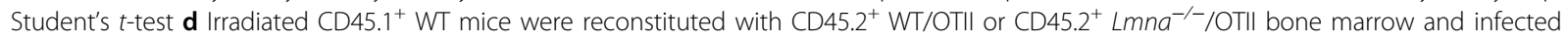
intraperitoneally with VACV-OVA. After 5 days, peritoneal exudate was analyzed ( $n=9$ and 6 mice from 2 independent experiments). Data are means \pm SEM analyzed by unpaired Student's $t$-test. e Irradiated CD45. $1^{+} / C D 45.2^{+}$WT mice were reconstituted with a mix of CD45. $1^{+}$WT/OTII with CD45.2 ${ }^{+}$ $\mathrm{Lmna}^{-/-}$/OTII bone marrow. Five days after VACV-OVA intradermal infection in the footpad, popliteal lymph nodes were analyzed $(n=9$ and 9 mice from 2 independent experiments). Data are means \pm SEM analyzed by paired Student's $t$-test. ${ }^{*} P<0.05 ;{ }^{* *} P<0.01$; ${ }^{* * *} P<0.001$
} 


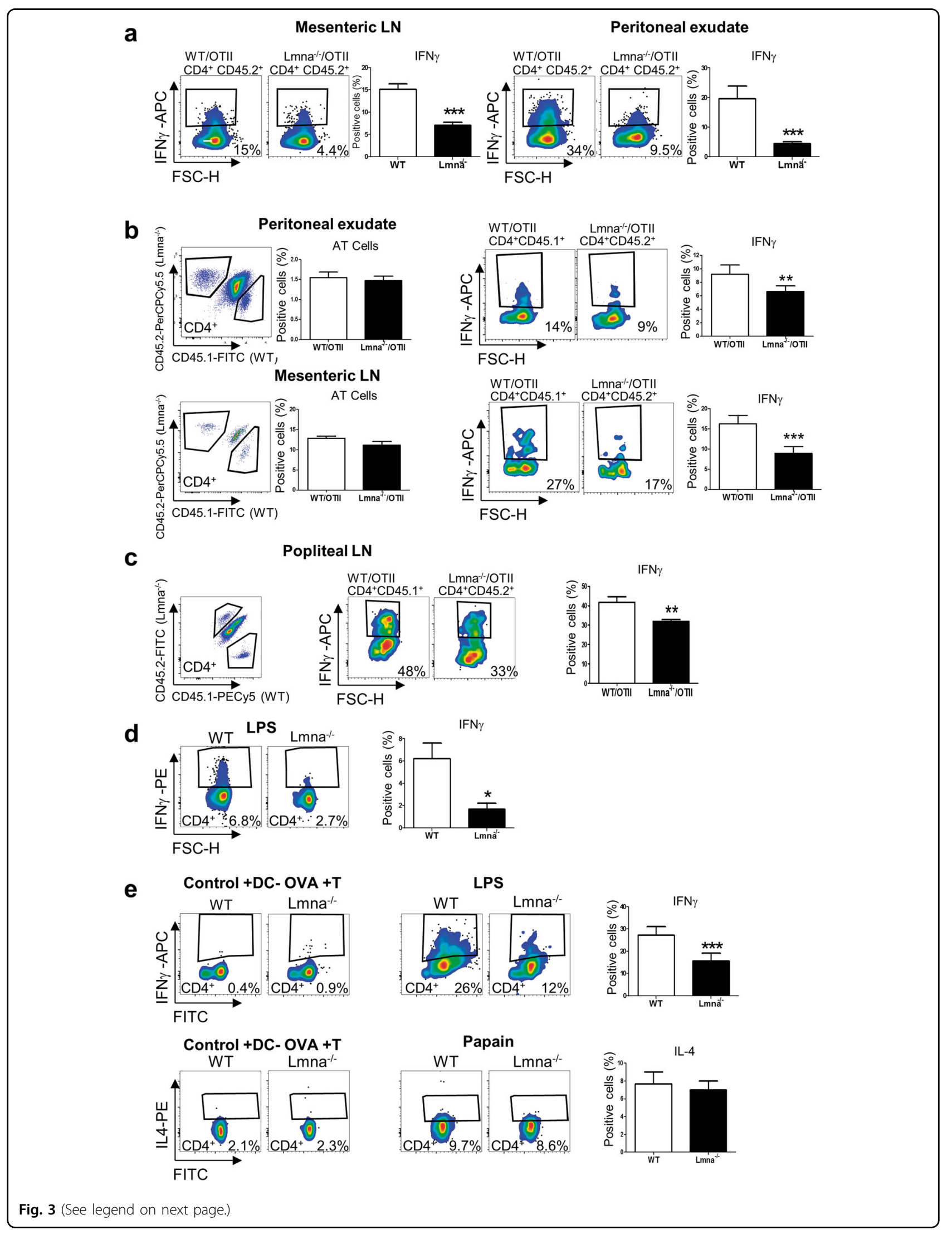


intestine than mice receiving WT CD4 ${ }^{+}$T-cells (Fig. 6c). In addition, we found that lamin $\mathrm{A} / \mathrm{C}$ expression in $\mathrm{CD} 4^{+}$ $\mathrm{T}$-cells differentiated to Th1 in vitro positively regulates the mRNA expression of eomes, Blimp1, GzmB, and Prf1 but not granzyme A (GzmA) (Figure S3). Lamin A/C also regulates $\mathrm{CD}^{+}{ }^{+}$T-cell cytoxicity in vivo, since VACVOVA-generated $L m n a^{-/-}$Th1 cells were less efficient to

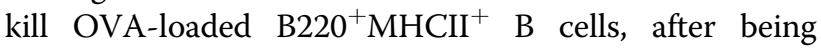
adoptively transferred to $\mathrm{Ragl}^{-/}$mice (Figure S4).

We also analyzed the importance of lamin A/C expression for Th1 responses against the intracellular parasite L. major ${ }^{16}$. Mice on the C57BL/6 background control $L$. major infection by developing a protective Th1 response $^{20}$. C57BL/6 mice lacking lamin $\mathrm{A} / \mathrm{C}$ in the whole immune system (Fig. 6d-h) or specifically in T-cells (Fig. 6i-k) developed progressively larger and non-healing lesions (Fig. 6d, e, i) after inoculation of the ear dermis with a low dose of $L$. major parasites. This effect correlated with a higher parasite burden in the infection site and in draining lymph nodes after 3 weeks (Fig. 6f, j). At this time, $\mathrm{Lmna}^{-/-}$mice showed a reduced percentage of IFN $\gamma^{+} \mathrm{CD}^{+}{ }^{+}$T-cells (Fig. 6g, k), with less IFN $\gamma$ production (Fig. 6h). These results further support the role of lamin $\mathrm{A} / \mathrm{C}$ in $\mathrm{Th} 1$ responses against pathogens.

\section{Discussion}

The role of nuclear envelope proteins in the regulation of immune homeostasis remains largely unknown ${ }^{21}$. Similarly, little is known about the molecular signals that switch immune function from protective to tissue damaging. Adaptive immunity is finely regulated by the interplay between immune regulatory mechanisms and effector T-cell responses. T-cells play central roles in orchestrating the protection against diverse microbial pathogens ${ }^{4}$. Many studies have investigated membrane mediators important for T-cell fate decision, while others have assessed the role of cytoplasmic proteins; however, the importance of nuclear envelope proteins for naive $\mathrm{T}$ cell differentiation remained overlooked. Despite studies characterizing signaling pathways from the membrane to the nucleus, there is a lack of information about signals arising in the nuclear interior and the role of nuclear proteins in mediating the transmission of information to the cytoplasm. It has been previously shown that intrinsic lamin A/C deficiency does not affect $\mathrm{T}$ - and B-cell development, driving the generation of functional and self-MHC-restricted $\mathrm{CD} 4^{+}$and $\mathrm{CD} 8^{+} \mathrm{T}$-cells ${ }^{10}$. We previously demonstrated that transient lamin $\mathrm{A} / \mathrm{C}$ expression in $\mathrm{CD}^{+} \mathrm{T}$-cells after antigen recognition contributes to T-cell activation ${ }^{3}$. In the present study, we have identified the nuclear envelope protein lamin $\mathrm{A} / \mathrm{C}$ as a crucial driver of Th1 polarization, both in vitro and in vivo.

Lamin A/C is expressed upon T-cell activation, and its deficiency downregulates the transcription factor T-bet, thereby impairing naive $\mathrm{CD} 4^{+} \mathrm{T}$-cell differentiation toward the Th1 phenotype. Strikingly, this effect is not counterbalanced by an increase in Th2 differentiation. Distinct signaling pathways can drive $\mathrm{T}$-cell differentiation ${ }^{22}$. In response to TCR activation and mTOR costimulation, Akt modulates transcription of T-bet but not Gata3, thus affecting Th1 but not Th2 differentiation. In contrast, PKC$\theta$ activation yields the opposite result ${ }^{22}$. Lamin $\mathrm{A} / \mathrm{C}$ is an important regulator of gene transcription during adipose tissue differentiation ${ }^{23}$ and controls the phosphorylation of signaling molecules in other cellular contexts ${ }^{1,24}$. Indeed, we previously showed that lamin A/C binds to ERK $1 / 2$ and c-Fos, regulating AP-1 transcription factor target genes ${ }^{24,25}$ and that lamin $\mathrm{A} / \mathrm{C}$ controls $\mathrm{CD}^{+}{ }^{+} \mathrm{T}$-cell activation through ERK1/2 signaling ${ }^{3}$. Interestingly, the formation of c-Fos/c-Jun dimers can potentiate Th1 differentiation ${ }^{26}$. Lamin $\mathrm{A} / \mathrm{C}$ thus seems to specifically regulate pathways involved in Th1 differentiation, directly modulating the transcription of Th1-related genes. This process occurs in a TCR-dependent manner, although lamin $\mathrm{A} / \mathrm{C}$ can also regulate signaling downstream the TCR, as observed after stimulation with PMA plus ionomycin.

The Th fate of antigen-engaged T-cells depends on many factors, including the type of antigen encountered,

\footnotetext{
(see figure on previous page)

Fig. 3 Compromised in vivo Th1 differentiation of naive $\mathrm{CD}^{+}$T-cells from $\mathrm{Lmna}^{-/-}$mice. Percentage of IFNY ${ }^{+} \mathrm{CD} 4^{+} \mathrm{T}$-cells. a Recipient CD45.1 $1^{+}$WT mice were adoptively transferred with CD45.2 $2^{+}$WT/OTII or CD45.2 $2^{+} \mathrm{Lmna}^{-/-} / \mathrm{OTII} \mathrm{CD} 4^{+} \mathrm{T}$-cells. Five days after intraperitoneal VACV-OVA infection, mesenteric lymph nodes and the peritoneal exudate were analyzed ( $n=10 \mathrm{WT}$ and $9 \mathrm{Lmna}^{-1-}$ mice from 2 independent experiments). Data are means \pm SEM analyzed by unpaired Student's t-test. $\mathbf{b}$ CD45. $1^{+} / \mathrm{CD} 45.2^{+}$WT mice were adoptively transferred (AT) with a mix of CD45. $1^{+}$WT/ OTII and CD45.2 $2^{+} \mathrm{Lmna}^{-/} / \mathrm{OTII} \mathrm{CD} 4^{+}$T-cells and infected intraperitoneally with VACV-OVA. After 5 days, peritoneal exudate and mesenteric lymph nodes were analyzed ( $n=11$ and 11 mice from 2 independent experiments) Data are means \pm SEM analyzed by paired Student's $t$-test. c CD45. $1^{+} /$ CD45.2 $2^{+}$WT mice were AT as in $\mathbf{b}$, and after 5 days of intradermal infection with VACV-OVA the popliteal lymph nodes were analyzed $(n=6$ and 6 mice from 2 independent experiments). Data are means \pm SEM analyzed by paired Student's $t$-test $\mathbf{d}$ OVA-loaded LPS-matured BMDCs were AT to WT recipient mice. After $18 \mathrm{~h}$, recipients received intravenous injections of a mix of CD $45.1^{+} \mathrm{WT}$ and CD $45.2^{+} \mathrm{Lmna} \mathrm{m}^{-/} / \mathrm{OT} / \mathrm{CD} 4^{+}$naive T-cells. Four days later, the popliteal lymph nodes were analyzed ( $n=3$ and 3 mice from 1 representative experiment out of 2). Data are means \pm SEM analyzed by unpaired Student's t-test e Isolated splenic CD11 $\mathrm{c}^{+}$cells were incubated with OVA and LPS or with OVA and papain for $4 \mathrm{~h}$ and then AT to WT recipients. Control mice were transferred with $C D 11 c^{+}$cells in the absence of OVA (DC-OVA). After $18 \mathrm{~h}$, recipients received intravenous injections of a mix of CD45.1 $1^{+}$WT and CD45.2 $2^{+} \mathrm{Lmna}^{-/-} \mathrm{CD} 4^{+}$naive T-cells. Four days later, the popliteal lymph nodes were analyzed. The percentage of IL $4^{+} \mathrm{CD} 4^{+}$ T-cells was also investigated ( $n=4$ and 4 mice from 2 independent experiments). Data are means \pm SEM analyzed by unpaired Student's $t$-test. ${ }^{*} P<$ $0.05 ;{ }^{* *} P<0.01 ;{ }^{* * *} P<0.001$
} 


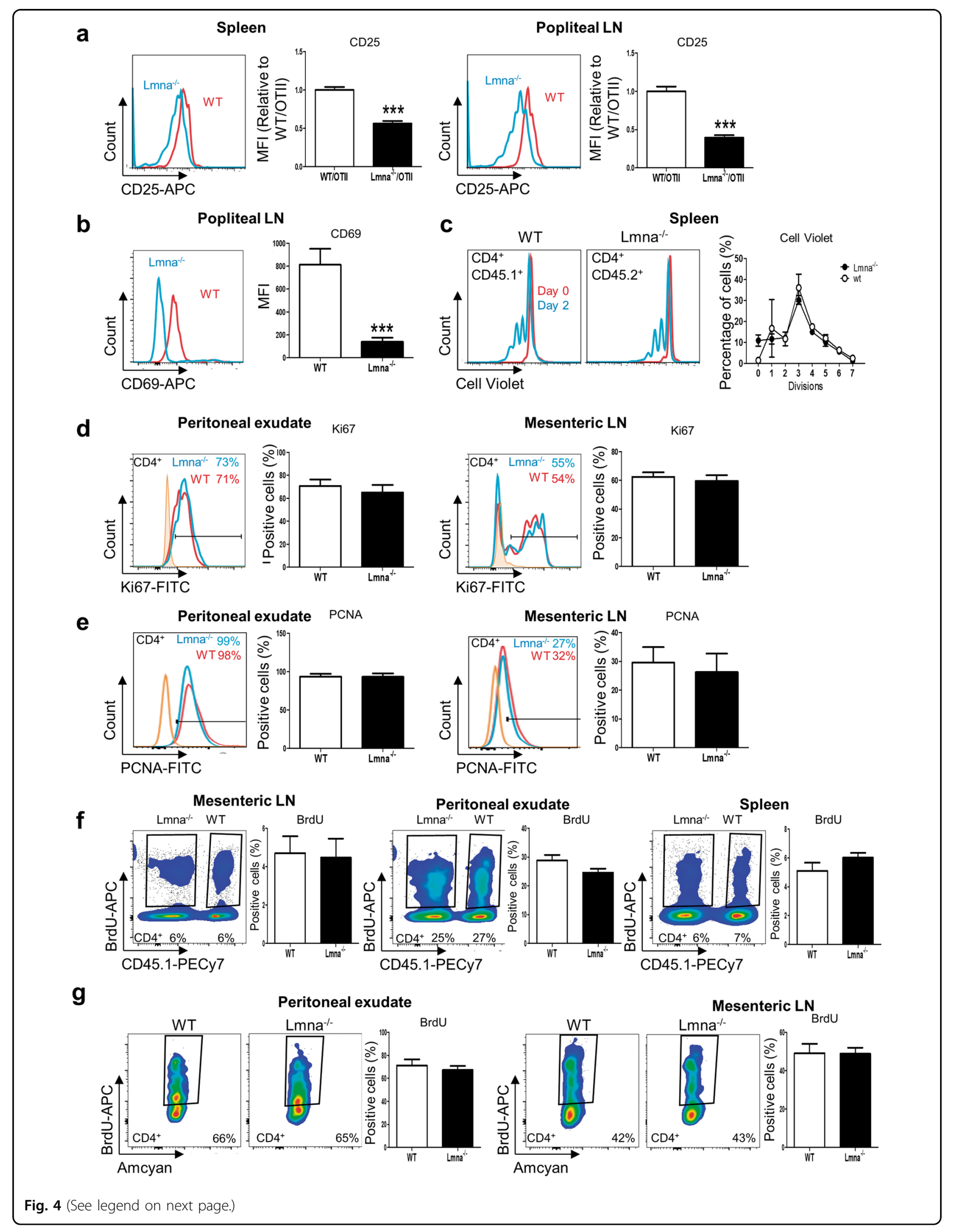


the TCR signal intensity, the duration of antigen presentation, and the local cytokine milieu ${ }^{4,6-8,26,27}$. Th1 differentiation is favored by stronger $\mathrm{T}$-cell activation signals and longer T-DC cell-cell interactions ${ }^{8,26}$. Lamin $\mathrm{A} / \mathrm{C}$ enhances $\mathrm{T}$-cell activation by increasing TCR signal strength and promoting T-DC interaction ${ }^{3}$. Weaker TCR signal intensity in the absence of lamin $\mathrm{A} / \mathrm{C}$ could account for the observed reduction in $\mathrm{CD}^{+} \mathrm{T}$-cell activation triggered by VACV infection. However, this cannot fully explain the differences in Th1 vs. Th2 differentiation in lamin $\mathrm{A} / \mathrm{C}$-deficient $\mathrm{T}$-cells, indicating that additional factors are involved. Regarding the cytokine milieu, IL-2, IL-12, and IFN $\gamma$ are known to facilitate Th1 differentiation, whereas IL-4 favors Th2 differentiation. Moreover, some cytokines promote differentiation to a specific Th phenotype without affecting others. For example, IL-33 enhances Th1 but not Th2 polarization in the presence of IL-12 ${ }^{28}$. Lamin A/C expression could regulate the production and release of cytokines important for Th1 phenotype. In this regard, we find that lamin A/C deficiency reduces membrane expression of the IL-2 receptor CD25 in $\mathrm{CD}_{4}{ }^{+} \mathrm{T}$-cells activated by VACV infection in vivo. Incubation of $\mathrm{CD} 4^{+} \mathrm{T}$-cells with IL-2 or Th1 polarizing cytokines during in vitro differentiation did not rescue the impaired $L m n a^{-1-}$ Th1 differentiation, indicating that intracellular signals driven by the nuclear envelope protein lamin $\mathrm{A} / \mathrm{C}$ directly regulate Th1 differentiation.

Viral clearance requires the efficient coordination of multiple immune effector mechanisms ${ }^{11}$. We show that lamin $\mathrm{A} / \mathrm{C}$ deficiency in $\mathrm{CD} 4^{+} \mathrm{T}$-cells results in a defective Th1 differentiation, impairing the response against VACV and delaying viral clearance. These results suggest that lamin $\mathrm{A} / \mathrm{C}$ is an essential component of the immune response against cytopathic viruses. Remarkably, the role of lamin $\mathrm{A} / \mathrm{C}$ in viral clearance seems to be $\mathrm{CD} 4^{+} \mathrm{T}$-cell dependent, since only $\mathrm{CD} 4^{+} \mathrm{T}$-cells were adoptively transferred to $\mathrm{T}$ - and B-cell-deficient $\mathrm{Rag1}^{-/-}$mice before mouse infection with VACV. Accordingly, in humans $\mathrm{CD}^{+}{ }^{+} \mathrm{T}$-cells are critical for antiviral immunity and control of VACV replication ${ }^{12} \cdot \mathrm{CD}^{+} \mathrm{T}$-cells can also regulate innate immune responses that mediate viral clearance ${ }^{11}$, which is independent on B-cells and $C D 8^{+} \mathrm{T}$ cells, and might be important for appropriate $\mathrm{CD} 4^{+} \mathrm{T}$-cell responses against $\mathrm{VACV}^{17}$. Interestingly, $\mathrm{Lmna}^{-/-} \mathrm{CD} 4^{+}$ $\mathrm{T}$-cells show reduced cytotoxic activity in vivo and impaired in vitro mRNA expression of transcription factors involved in the regulation of $\mathrm{CD} 4^{+} \mathrm{T}$-cell cytotoxicity, like eomes, Blimp1, GzmB, and Prf1.

The protozoan parasite L. major cause cutaneous leishmaniasis ${ }^{29}$, usually provoking local self-healing skin lesions in humans. However, the parasite can cause prolonged non-healing skin ulcers with extensive tissue destruction and become systemically distributed ${ }^{29}$. C57BL/6 mice develop protective immune responses against $L$. major. We show that WT recipient C57BL/6 mice reconstituted with $L m n a^{-1-}$ bone marrow develop poorer Th1 responses against this parasite, with worse pathogen clearance than recipients of WT cells. The immune response against $L$. major involves multiple cell types. Importantly, our results clearly demonstrate that lack of lamin A/C specifically in T-cells impaired healing of ear lesions. C57BL/6 mice develop Th1-dependent responses to $L$. major, and following a high $L$. major dose the lesions heal in the absence of $\mathrm{CD}^{+} \mathrm{T}^{-}$-cells ${ }^{30,31}$. Moreover, cytolytic $\mathrm{CD}^{+} \mathrm{T}$-cells are pathogenic when recruited to Leishmania lesions in large numbers ${ }^{32}$. Therefore, impaired responses observed in Lmna ${ }^{\text {flox/ }}$ ${ }^{\text {flox }} \times$ CD4-CRE mice likely associate with lamin A/Cdeficient $\mathrm{CD}^{+}{ }^{+} \mathrm{T}$-cells. The early immune response determines whether $L$. major skin lesions will be selfhealing or chronic. C57BL/6 mice develop $\mathrm{CD}^{+}$Th1 cell-mediated resistance, whereas other mouse strains develop $\mathrm{CD}^{+}{ }^{+} \mathrm{Th} 2$ responses and are extremely susceptible to infection ${ }^{33}$. Therefore, $\mathrm{CD}^{+}{ }^{+} \mathrm{Th} 1$ cells are crucial for reducing Leishmania infection ${ }^{34}$, producing IFN $\gamma$, IL2 , and TNF $\alpha$ locally and leading to macrophage activation and parasite elimination. Our experiments show a diminished percentage of IFN $\gamma$-producing $\mathrm{CD}^{+}{ }^{+} \mathrm{T}$-cells

\footnotetext{
(see figure on previous page)

Fig. $4 \mathrm{Lmna}^{-/-} \mathrm{CD}^{+}$T-cells show impaired in vivo and in vitro activation in response to VACV infection. $\mathbf{a}, \mathbf{b}$ WT CD $45.1^{+} / \mathrm{CD} 45.2^{+}$mice were

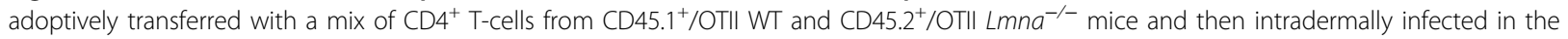
footpad with VACV-OVA for 2 days. Spleen and popliteal lymph nodes were analyzed, and the expression of $\mathbf{a}$ CD25 and $\mathbf{b}$ CD69 was quantified $(n=$

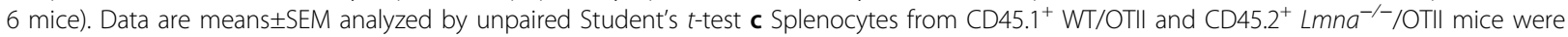
mixed, stained with cell violet, and cultured in the presence of OVA for 2 days. CD4 ${ }^{+}$T-cell proliferation was quantified and the number of cell divisions is shown in the graph. Data are means \pm SEM of six independent experiments analyzed by two-way ANOVA with Bonferroni's multiple comparison test. $\mathbf{d}$, e CD4 $4^{+}$T-cells from CD45.1 $1^{+} \mathrm{WT}$ and $\mathrm{CD} 45.2^{+} \mathrm{Lmna}^{-/-}$mice were mixed 1:1 and adoptively transferred to CD45.1/CD45.2 WT mice. Recipient mice were then intraperitoneally infected with VACV for 7 days. The peritoneal exudates and mesenteric lymph nodes were analyzed, and the percentage of $\mathbf{d} \mathrm{Ki}_{6}{ }^{+}$or e PCNA ${ }^{+} \mathrm{CD}^{+}{ }^{+}$T-cells was quantified ( $n=5$ mice from 2 independent experiments) Data are means \pm SEM analyzed

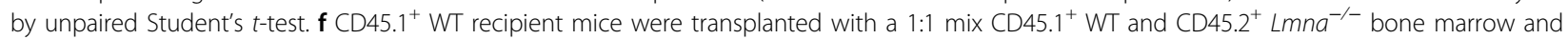
infected intraperitoneally with VACV. Mice were injected with BrdU, and $24 \mathrm{~h}$ later the percentage of $\mathrm{BrdU}^{+} \mathrm{CD} 4^{+} \mathrm{T}$-cells was quantified in mesenteric lymph nodes, peritoneal exudate, and spleen ( $n=3$ mice from 1 representative experiment) Data are means \pm SEM analyzed by paired Student's $t$-test. g CD4 ${ }^{+}$T-cells from CD45.2 $2^{+}$WT or CD45.2 $2^{+} \mathrm{Lmna}^{-/-}$mice were mixed 1:1 and adoptively transferred to CD45. $1^{+} / \mathrm{CD} 45.2^{+}$WT mice. Recipient mice were infected intraperitoneally with VACV for 6 days and injected with BrdU. After $24 \mathrm{~h}$, the percentage of BrdU ${ }^{+} \mathrm{CD} 4^{+}$T-cells was quantified in the peritoneal exudate and mesenteric lymph nodes ( $n=5$ and 5 mice). Data are means \pm SEM analyzed by paired Student's $t$-test. ${ }^{* * *} P<0.001$
} 
and reduced IFN $\gamma$ production in $L m n a^{-1-}$ mice. IFN $\gamma$ secretion by $\mathrm{CD}^{+}{ }^{+} \mathrm{T}$-cells induces macrophages to produce nitric oxide and TNF, thus controlling L. major infection $^{33,35}$. This mechanism could explain the diminished pathogen clearance observed in the absence of lamin A/C. Importantly, we show that lamin $\mathrm{A} / \mathrm{C}$ in $\mathrm{CD} 4^{+}$

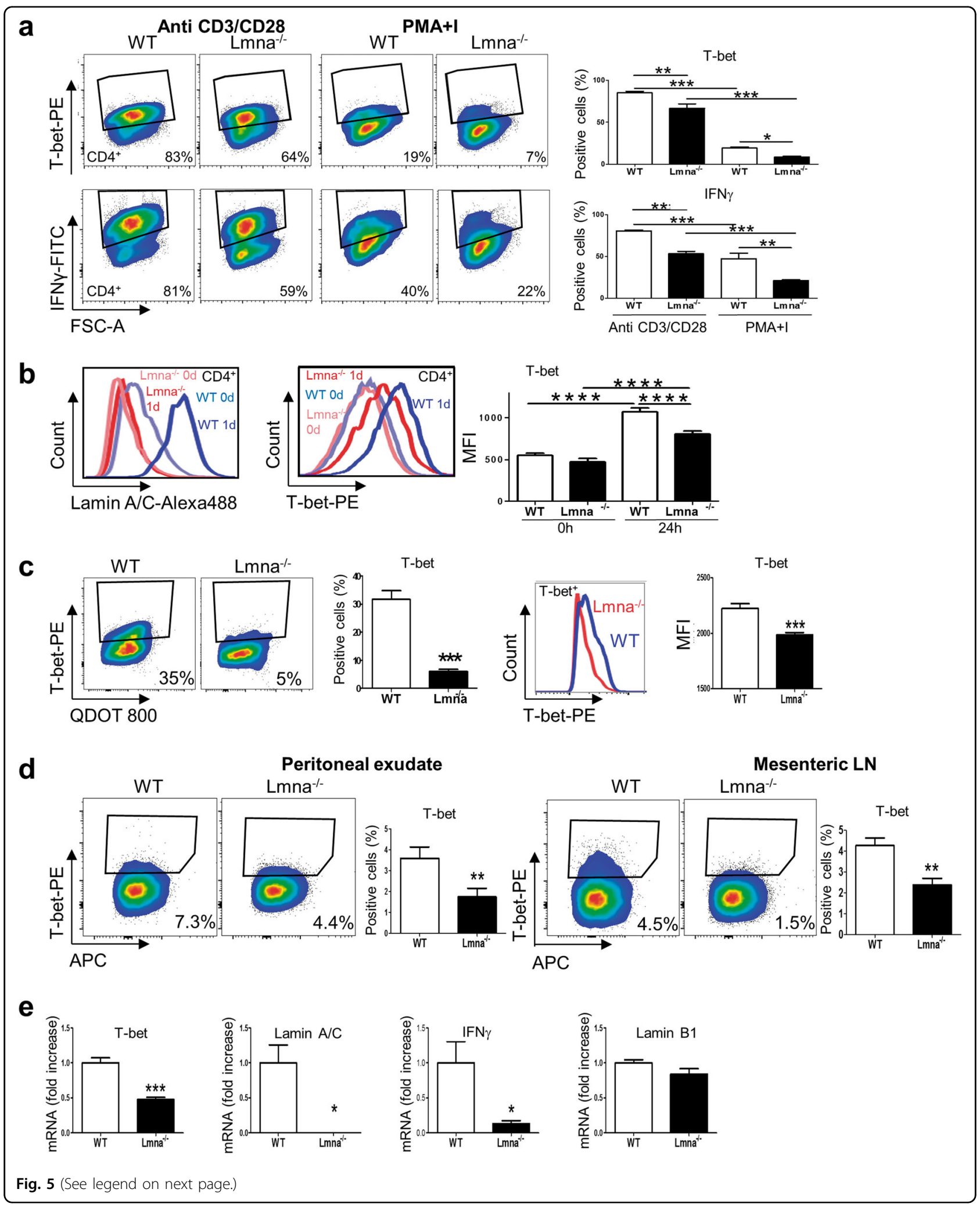


T-cell is an important mediator of the immune control against this pathogen.

Our study reveals a novel role for lamin $\mathrm{A} / \mathrm{C}$ as a regulator of T-cell differentiation, controlling the maintenance of Th1 populations in response to pathogen infections. These data contribute to the understanding of the molecular mechanisms driving $\mathrm{CD} 4^{+} \mathrm{T}$-cell responses and suggest that strategies to modulate $\mathrm{T}$-cell function could provide a route toward therapeutic immunization and long-lasting protection.

\section{Materials and methods \\ Mice}

Lmna $^{-1-}$ mice have been described previously ${ }^{36}$. C57BL/6-Tg (TcraTcrb)425Cbn/J mice (OTII mice) express a TCR specific for the OVA peptide (amino acid residues 323-339) in the context of I-Ab and the CD4CRE and were obtained from the Jackson Laboratory (stock number 004194 and 017336, respectively). C57BL/ 6-CD45.2 Lmna $^{-1-}$ OTII mice were generated by crossing C57BL/6-CD45.2 ${ }^{+}$OTII mice with C57BL/6CD 45.2 $2^{+}$mna $^{-/-}$mice. C57BL/6-CD45.1 ${ }^{+} \mathrm{CD} 45.2^{+} \mathrm{WT}$ mice were generated by crossing $\mathrm{C} 57 \mathrm{BL} / 6-\mathrm{CD} 45.2^{+}$mice with C57BL/6-CD45.1 $1^{+}$mice. C57BL/6-CD45.1 $1^{+}$and C57BL/6-CD $45.1^{+} \mathrm{CD} 45.2^{+} \mathrm{WT}$ mice were used as recipients for adoptive transfer. C57BL/6-CD $45.1^{+} \mathrm{CD} 45.2^{+}$/ OTII WT mice were generated by crossing C57BL/6CD45.2 $2^{+} / \mathrm{OTII}$ mice with C57BL/6-CD45.1 $1^{+}$OTII mice. $L m n a^{\text {flox/flox }}$ mice were kindly provided by Y. Zheng ${ }^{37}$. C57BL/6Lmna ${ }^{\text {flox/flox }}$ CD4-CRE mice were generated by crossing C57BL/6-CD4-CRE with C57BL/6-Lmna ${ }^{\text {flox/flox }}$ mice. C57BL/6 transgenic $\beta$-actin DsRed mice (Tg (ACTB-DsRed"MST)1Nagy/J; The Jackson Laboratory) was also used. All mice were bred at the CNIC in specific pathogen-free conditions.

Animal experiments were approved by the local ethics committee and the Spanish Ministry of Agriculture and Fisheries, Food and Environment. All animal procedures conformed to EU Directive 86/609/EEC and Recommendation 2007/526/EC regarding the protection of animals used for experimental and other scientific purposes, enforced in Spanish law under Real Decreto 1201/2005.

\section{Antibodies and reagents}

Anti-lamin-A/C (n-18), anti-p-ERK1/2, anti-PCNA, and PE-conjugated anti-lamin A/C were obtained from Santa Cruz Biotechnology. Alexa Fluor 488-conjugated antilamin-A/C was obtained from Cell Signaling. Anti-CD3, anti-CD28, fluorescein isothiocyanate (FITC)-conjugatedCD45.1, V450-conjugated anti-CD45.1, PerCPCy5.5conjugated anti-CD45.1, PerCPCy5.5-conjugated anti-CD45.2, APC-conjugated anti-CD45.1, v450conjugated anti-CD45.2, FITC-conjugated anti-CD45.2, APC-conjugated anti-IFN $\gamma$, and V450-conjugated antiCD4 were from Tonbo Bioscience. PECy5-conjugated anti-CD45.1, PECy7-conjugated anti-CD45.1, PEconjugated anti-Tbet, FITC-conjugate anti-CD8, APCconjugated anti-CD69, APC-conjugated anti-CD25, PE-conjugated anti-T-bet, FITC-conjugated anti-Ki67, PE-conjugated anti-IL-4, and biotinylated antibodies against B220, CD19, MHCII, CD11c, CD11b, CD44, CD49b, IgM CD25, and CD8 $\alpha$ were from BD Biosciences.

\section{T-cell stimulation and polarization}

$\mathrm{CD} 4{ }^{+} \mathrm{CD} 25^{-}$T-cells from spleens were purified by negative selection on separation columns (Miltenyi Biotec) after labeling the cells with a cocktail of biotinylated antibodies against B220, CD19, MHCII, CD11c, CD11b, CD44, $\mathrm{CD} 25$, CD49b, IgM, and CD8 $\alpha$ and a solution containing streptavidin-bound magnetic microbeads (Miltenyi Biotec). For polarizing experiments, $\mathrm{CD} 4^{+} \mathrm{CD} 25^{-}$T-cells from WT/OTII and Lmna ${ }^{-/-} /$OTII mice were stimulated with irradiated autologous WT APCs previously incubated with OVA peptide $(10 \mu \mathrm{g} / \mathrm{ml})$ for $30 \mathrm{~min}$ at $37^{\circ} \mathrm{C} . \mathrm{CD} 4^{+} \mathrm{CD} 25^{-}$ T-cells from WT and $L m n a^{-1-}$ mice were stimulated with plate-bound anti-CD3 $(10 \mu \mathrm{g} / \mathrm{ml})$ and soluble anti-CD28 antibodies $(2 \mu \mathrm{g} / \mathrm{ml})$.

Polarizing conditions were as follows: for Th1 polarization: IL-12 $(10 \mathrm{ng} / \mathrm{ml})$ and anti-IL-4 $(4 \mu \mathrm{g} / \mathrm{ml})$, with only IL-2 $(10 \mathrm{ng} / \mathrm{ml})$ during the rest period; for $\mathrm{Th} 2$ polarization: IL-4 $(10 \mathrm{ng} / \mathrm{ml})$ and anti-IFN $\gamma(4 \mu \mathrm{g} / \mathrm{ml})$, with only IL-2 $(10 \mathrm{ng} / \mathrm{ml})$ during the rest period. Antibodies and cytokines were from BD bioscience and Tonbo, respectively. Cells were cultured in RPMI-1640 medium (GIBCO) for the indicated times.

\section{(see figure on previous page)}

Fig. $5 \mathrm{Lmna}^{-/-} \mathrm{CD}^{+}$T-cells show impaired in vitro and in vivo T-bet expression. a Percentage of IFNy ${ }^{+}$and T-bet ${ }^{+}$cells after stimulation of $\mathrm{CD}^{+}{ }^{+}$-cells from WT and $\mathrm{Lmna}^{-1-}$ mice with anti-CD3/CD28 antibodies or PMA plus ionomycin for 4 days in the presence of IL-2 (Data are means \pm SEM of at least 2 independent experiments analyzed by one-way ANOVA with Bonferroni's multiple comparison test. $\mathbf{b}$ T-bet and lamin A/C expression in WT and $\mathrm{Lmna}^{-/-} \mathrm{CD}^{+} \mathrm{T}$-cells $48 \mathrm{~h}$ after stimulation with anti-CD3/CD28 antibodies ( $n=12$ and 12 mice). Data are means $\pm S E M$ analyzed by one-way ANOVA with Bonferroni's multiple comparison test $\mathbf{c}$ Percentage of T-bet ${ }^{+}$cells after stimulation of WT and $L m n a^{-/-} \mathrm{CD}^{+} \mathrm{T}-$ cells with anti-CD3/CD28 for 7 days in the presence of Th1 polarizing antibodies and cytokines ( $n=5$ and 6 mice from 2 independent experiments). Data are means \pm SEM analyzed by unpaired Student's $t$-test $\mathbf{d}$ Percentage of T-bet ${ }^{+}$CD4 ${ }^{+}$T-cells in peritoneal exudates and mesenteric lymph nodes of WT recipient mice reconstituted with a 1:1 mix of WT and $L m n a^{-/-}$bone marrow and intraperitoneally infected with VACV for 6 days ( $n=4$ and 4 mice from 2 independent experiments). Data are means \pm SEM analyzed by paired Student's t-test e RT-qPCR analysis of the indicated genes in WT and $\mathrm{Lmna}^{-/-} \mathrm{CD}^{+}$T-cells stimulated in vitro with anti-CD3/CD28 antibodies ( $n=$ pools of 3 mice). Data are means \pm SEM from 3 independent experiments analyzed by unpaired Student's $t$-test ${ }^{*} P<0.05$; ${ }^{* *} P<0.01$; ${ }^{* *} P<0.001 ;{ }^{* * *} P<0.0001$ 


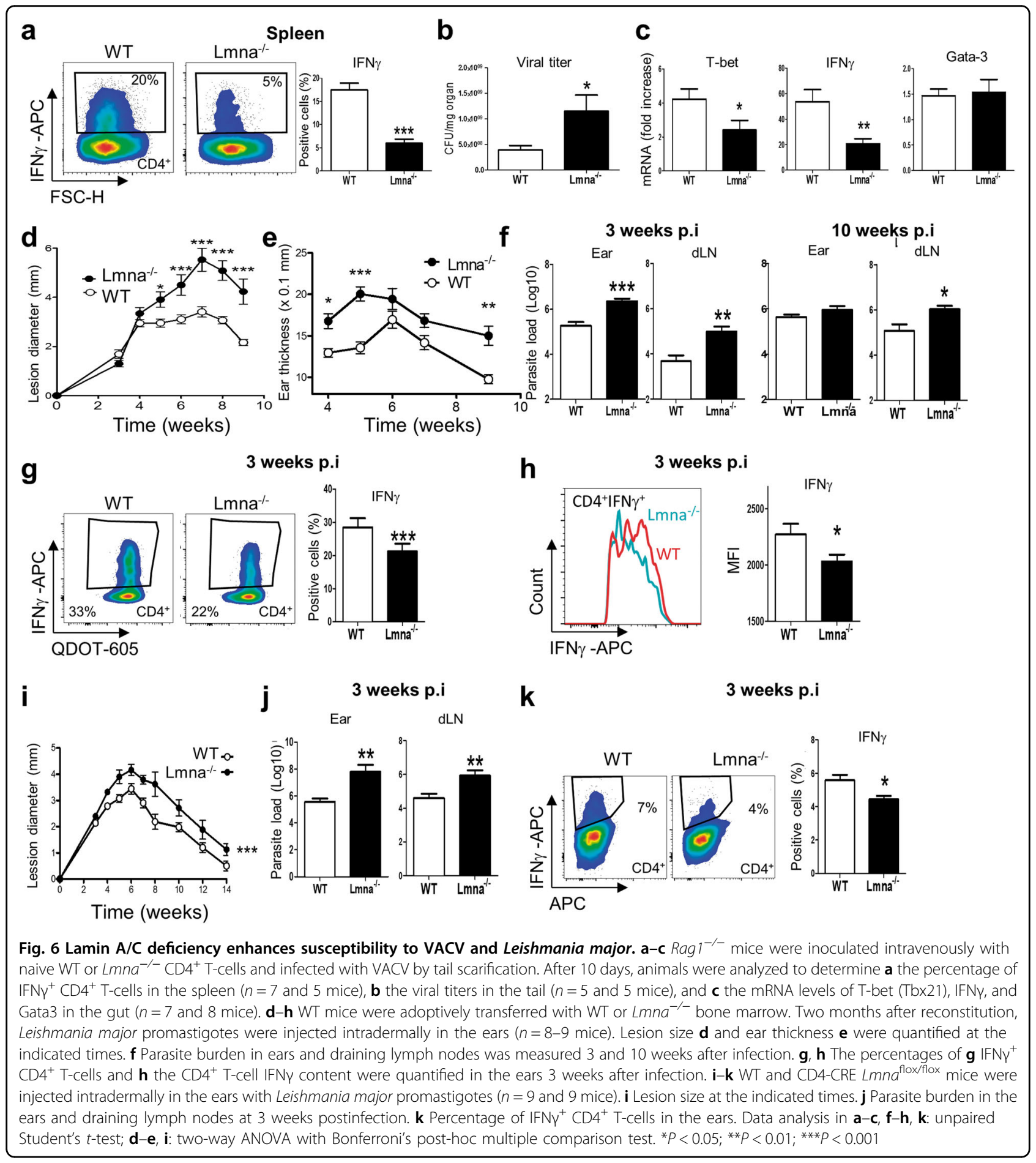

\section{Adoptive transfer}

Splenic CD4 ${ }^{+} \mathrm{CD} 25^{-} \mathrm{T}$-cells from CD45.2 $\mathrm{Lmna}^{-/-}$, $\mathrm{CD} 45.1^{+} \mathrm{CD} 45.2^{+} \mathrm{WT}$, or CD45.2 $2^{+} \mathrm{WT}$ mice were isolated by negative selection on MACS separation columns (Miltenyi Biotec) after labeling the cells with a cocktail of biotinylated antibodies against B220, CD19, MHCII, CD11c, CD11b, CD44, CD25, CD49b, IgM, and CD8 $\alpha$, as well as with a solution containing streptavidin-bound magnetic microbeads (Miltenyi Biotec). Adoptive transfer experiments were performed by inoculating CD45.1 ${ }^{+}$or CD $45.1^{+} \mathrm{CD} 45.2^{+} \mathrm{WT}$ recipient mice with $1 \times 10^{6}$ isolated CD4 ${ }^{+}$T-cells. In some experiments, CD $45.1^{+} \mathrm{CD} 45.2^{+}$ WT recipient mice were inoculated with a $1: 1$ mix of $2 \times$ $10^{6}$ CD25-CD4 ${ }^{+}$T-cells obtained from the spleens of 
CD 45.2 $2^{+}$Lmna $^{-/-}$and CD45.1 $1^{+}$WT mice. In VACV experiments, adoptive cell transfer was performed $24 \mathrm{~h}$ before inoculation with the VACV virus ${ }^{38}$. Similar adoptive transfers were performed with $\mathrm{CD} 4^{+} \mathrm{T}$-cells isolated from CD45.1 ${ }^{+} \mathrm{CD} 45.2^{+} \mathrm{WT} / \mathrm{OTII}, \mathrm{CD} 45.1^{+} \mathrm{WT} / \mathrm{OTII}$, or $\mathrm{CD} 45.2^{+} \mathrm{Lmna}^{-1-}$ mice.

\section{Generation of BMDCs}

BMDCs were generated as described in ref. 39. BMDCs were obtained from bone marrow cell suspensions after culture on non-treated cell culture dishes in complete RPMI 1640 medium supplemented with $10 \%$ fetal bovine serum (FBS), $2 \mathrm{mM}$ L-glutamine, $100 \mathrm{mg} / \mathrm{ml}$ penicillin, $100 \mathrm{mg} / \mathrm{ml}$ streptomycin, $50 \mathrm{mM} \mathrm{2-ME}$, and $20 \mathrm{ng} / \mathrm{ml}$ GM-CSF (PeproTech, London, UK). Cells were collected at day 9 and BMDCs were isolated as CD11c+ MHC-II+ Ly6G- cells. Maturation was induced after overnight incubation with LPS from Escherichia coli O111:B4 (1 $\mu \mathrm{g} /$ ml; Sigma-Aldrich).

\section{Vaccinia virus, scarification assays, and viral titration in organs}

The VACV strain Western Reserve (WR, ATCC number VR-1354) was a gift from Jonathan W. Yewdell and Jack R. Bennink (NIH, Bethesda, Maryland, USA). VACV was propagated in BSC-40 cells and purified by sucrose gradient ultracentrifugation. WT or OVA-expressing VACV $\left(1 \times 10^{6}\right.$ plaque-forming units $)$ were administered by intraperitoneal injection or intradermal injection in the footpad ${ }^{38}$.

Animals were anesthetized with an intraperitoneal injection of Ketamine $(100 \mathrm{mg} / \mathrm{kg}$ body weight) and Xylazine $(10 \mathrm{mg} / \mathrm{kg})$ diluted in sterile phosphate-buffered saline (PBS). Thirty $1 \mathrm{~cm}$ scarifications were made with a $26 \mathrm{G}$ syringe along the base of the tail, avoiding bleeding $^{40}$. Then $10 \mathrm{ml}$ of PBS containing $10^{7}$ VACV plaqueforming units (p.f.u.) were added to the area and allowed to air dry. For mock infection only, PBS was added.

Animals were euthanized and the tail aseptically removed, weighed, frozen at $-80^{\circ} \mathrm{C}$, and stored at $-80^{\circ} \mathrm{C}$ until use. The samples were homogenized with a Tissue Ruptor (QIAGEN, USA) in $0.5 \mathrm{ml}$ Dulbecco's modified Eagle's medium (DMEM) containing $100 \mathrm{U} / \mathrm{ml}$ penicillin and $100 \mu \mathrm{g} / \mathrm{ml}$ streptomycin. The homogenates were sonicated for $3 \mathrm{~min}$ at $40 \%$ amplitude, freeze-thawed twice $\left(-80^{\circ} \mathrm{C} / 37^{\circ} \mathrm{C}\right)$, sonicated again under the same conditions, and then serially diluted in DMEM without FBS. To quantify p.f.u., the dilutions were added to monolayers of $\mathrm{CV}-1$ cells seeded on 24-well plates. The cells were preincubated for 1 day at $37^{\circ} \mathrm{C}$ and $5 \% \mathrm{CO}_{2}$, the dilutions $(0.2 \mathrm{ml})$ were added to each well, and the cells were further incubated under the same conditions for $1 \mathrm{~h}$. After this, $0.5 \mathrm{ml}$ DMEM containing $0.5 \%$ FBS were added to each well. After $24 \mathrm{~h}$, the cells were stained for 5 min with crystal violet solution $(0.5 \%$ crystal violet, $10 \%$ ethanol, and $1 \%$ paraformaldehyde) and washed again. Viral plaques were counted and plaque number was multiplied by the reciprocal of sample dilution and converted to p.f.u./ g. ${ }^{17}$

\section{Leishmania parasites, preparation, inoculation, and quantification}

In vivo experiments were carried out using L. major Friedlin strain FV1 (MHOM/IL/80/Friedlin), generously provided by Dr. D. Sacks $(\mathrm{NIH})^{20}$. For Leishmania challenge, parasites were kept in a virulent state by passage in mice. Parasites were cultured and differentiated as described $^{41}$. Mice were infected by i.d. injection of $10^{3}$ or $5 \times 10^{4}$ metacyclic $L$. major promastigotes into the dermis of both ears. Lesion size in the ear was determined with digital callipers (Duratool) ${ }^{20}$. The limiting dilution assay was used to determine parasite number ${ }^{41}$. Parasite load was expressed as the number of parasites in the whole organ.

\section{Bone marrow transplantation}

WT recipient mice received 13 Gy of total body irradiation administered in two treatments from a ${ }^{137} \mathrm{Cs}$ source. Bone marrow cells from CD $45.2^{+} \mathrm{WT}$ or CD $45.2^{+} \mathrm{Lmna}^{-\prime}$ - mice were transplanted into CD45.1 ${ }^{+}$WT recipients by injection into the retro-orbital sinus immediately after irradiation. A mix 1:1 of bone marrow cells from CD45.1 $1^{+}$ WT and CD45.2 $2^{+}$Lmna $^{-1-}$ mice were transplanted into CD $45.1^{+} \mathrm{CD} 45.2^{+}$WT recipients by injection into the retro-orbital sinus immediately after irradiation. Approximately 8 weeks after transplantation, the chimeric condition of the mice was assessed by flow cytometric analysis of blood cells stained with a combination of fluorescently labeled anti-CD45.1 and anti-CD45.2 antibodies to detect $\mathrm{T}$-cells from donor and from recipient mice, which confirmed that $>90 \%$ of the cells analyzed were derived from the transplanted bone marrow cells

\section{Flow cytometry}

$\mathrm{CD}^{+}{ }^{+}$T-cells were stimulated with PMA $(20 \mathrm{ng} / \mathrm{ml})$ (Sigma Aldrich) plus ionomycin $(1 \mu \mathrm{g} / \mathrm{ml})$ (Sigma Aldrich) for $6 \mathrm{~h}$. Brefeldin A (Sigma Aldrich) was added for the last $2 \mathrm{~h}$ to allow intracellular cytokine accumulation. Surface antigens were stained with antibodies, then fixed and made permeable with either a Cytofix/Cytoperm kit (BD Pharmingen), then intracellular cytokines and transcription factors in cells were stained. Data were acquired on FACSCantoII or LSRFortessa flow cytometers (BD Biosciences) and analyzed with the BD FACSDIVA (BD Biosciences) or FlowJo (Treestar Inc) software.

\section{Reverse transcription-quantitative PCR}

Total RNA was isolated with Qiazol Lysis Reagent (Qiagen) and isopropanol precipitation or with the 
RNeasy Mini kit (Qiagen), according to the manufacturer's instructions. RNA concentration and purity were assessed from the ratio of absorbances at 260 and $280 \mathrm{~nm}$. Complementary DNA (cDNA) was synthesized from total RNA (0.1-1 $\mu$ g per reaction) with the High Capacity cDNA Reverse Transcription Kit (Applied Biosystems) using random primers and RNase Inhibitor, according to the manufacturer's protocol. Quantitative PCR was performed with the ABI PRISM 7900HT Sequence Detection System (Applied Biosystems) using the PCR Power SYBR Green PCR Master Mix (Applied Biosystems), with technical triplicates.

The sequences of RT-qPCR primers were as follows: T-Bet-Forward 5'-GAAAGGCAGAAGGCAGCAT-3'; T-Bet-Reverse 5'-GAGCTTTAGCTTCCCAAATGAA-3'; Hprt1-Forward 5'-CCTAAGATGAGCGCAAGTTGAA$3^{\prime}$ and Hprt1-Reverse 5'-CCACAGGACTAGAACACCT GCTAA-3'; GzmA-Forward 5'-GACTGCTGCCCACTGTAACG-3'; GzmA-Reverse 5'-TCAATATCTGTTGT TCTGGCTCCTTA-3'; GzmB-Forward 5'-TGTCTCTGG CCTCCAGGACAA-3'; GzmB-Reverse 5'- CTCAGGC TGCTGATCCTTGATCGA-3'; Prf1-Forward 5'- GCGT CTCCAGTGAATACAAAG-3'; Prf1-Reverse 5'- TACTT CGACGTGACGCT-3'; Eomes-Forward 5'-GCCTACCAAAACACGGATA-3'; Eomes-Reverse 5'-TCTGTT GGGGTGAGAGGAG-3'; Ifng-Forward 5'- TGGCTCT GCAGGATTTTCATG-3'; Ifng-Reverse 5'- TCAAGTGG CATAGATGTGGAAGAA-3'; Blimp-1-Forward 5'ACACACAGGAGAGAAGCCACATGA-3'; Blimp-1Reverse $5^{\prime}$ - TCGAAGGTGGGTCTTGAGATTGCT-3'; gapdh-Forward 5'-CTACACTGAGGACCAGGTTGTC3'; gapdh-Reverse 5'-GGTCTGGGATGGAAATTGTG3'. Lmnb1-Forward 5'-CAACTGACCTCATCTGGAAGAAC $\quad 3^{\prime} ; \quad$ Lmnb1-Reverse $\quad 5^{\prime}$-TAAGACTGTGCTTC TCTGAGC-3'; Lmna-Forward-5'-TGAGTACAACCTG CGCTCAC-3'; and Lmna-Reverse: 5'-TGACTAGG TTGTCCCCGAAG-3'. The extent of expression of a gene of interest was analyzed by the comparative $\mathrm{Ct}$ method with the Biogazelle qBasePLUS software using as internal control the housekeeping genes GAPDH (glyceraldehyde3-phosphate dehydrogenase) and HPRT1 (hypoxanthine phosphoribosyltransferase 1). Results are represented as fold change relative to control conditions.

\section{Proliferation assays}

Twenty-four hours before the sacrifice of the mice, a single dose of $1 \mathrm{mg}$ BrdU (BD Pharmingen) was injected intraperitoneally (i.p.). To assess BrdU incorporation, mesenteric lymph nodes, peritoneal exudate, and spleen were stained for $\mathrm{CD} 4$, fixed, and permeabilized using the BD BrdU Flow Kit (BD Pharmigen) according to the manufacturer's instructions. Cells were incubated at $37^{\circ} \mathrm{C}$ for $60 \mathrm{~min}$ in $30 \mu \mathrm{g}$ of DNase, followed by staining with anti-BrdU-FITC for $40 \mathrm{~min}$, washed, and analyzed by flow cytometry. Peritoneal exudate and mesenteric lymph node cells were fixed and permeabilized using Foxp3 fixation/ permeabilization buffer (BD Pharmingen) and stained for PCNA-FITC and Ki67-FITC.

\section{In vivo cytotoxicity assays}

Splenic CD $45.2^{+}$WT or CD $45.2^{+}$Lmna $^{-/-}$CD 4 /OTII $\mathrm{T}$-cells were isolated as described in the adoptive transfer

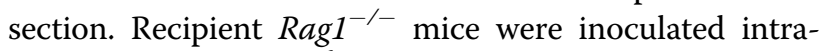
venously with $2 \times 10^{6}$ of either naive CD45.2/WT or CD45.2/Lmna ${ }^{-/-}$CD4 ${ }^{+} / \mathrm{OTII}$ T-cells and infected with VACV-OVA i.p. After 5 days, splenocytes from CD45.2/ WT/dsRED and CD45.1/WT mice were isolated and loaded or not with OVA OTII peptide, respectively. An approximately 1:1 mix of $5 \times 10^{6} \mathrm{CD} 45.2 / \mathrm{WT} / \mathrm{dsRED}$ and CD45.1/WT splenocytes was inoculated intravenously in the recipient $R a g 1^{-/-}$mice, which were previously inoculated and vaccinia infected. After $16 \mathrm{~h}$, animals were analyzed to determine the killing capacity of CD4/OTII cells in the spleen by flow cytometry. Killing capacity was determined as the ratio between CD45.2/WT/dsRED/ +OVA and CD45.1/WT/-OVA cells and the percentage of CD4/OTII T-cells. Mice adoptively transferred with CD4/OTII cells only and mice transferred with splenocytes in the absence of CD4/OTII cells were used as controls.

\section{Statistical analysis}

Statistical analyses were performed with Prism GraphPad or Microsoft Office Excel. Unless otherwise stated, statistical significance was calculated by two-tailed Student's $t$-test. When specified, one-way analysis of variance (ANOVA) or two-way ANOVA with Bonferroni's posthoc multiple comparison test was used. Significance of differences was calculated as follows: ${ }^{*} P<0.05,{ }^{* *} P<0.01$, *** $P<0.001$, and $* * 0.0001$.

\section{Acknowledgements}

The authors thank J. Mateos, I. Fernández-López, and M.J. Andrés-Manzano for technical assistance and S. Bartlett for English editing. This study was

supported by grants to J.-M.G.-G. from Instituto de Salud Carlos III (ISCIII) (PI14/ 00526, P117/01395, CP11/00145, CPII16/00022), the Miguel Servet Program, and Fundación Ramón Aréces; to V.A. (RD12/0042/0028 SAF2013-46663-R, SAF2016-79490-R); to F.S.-M. (SAF2014-55579-R, INDISNET-S2011/BMD-2332, ERC-2011-AdG 294340-GENTRIS, and PIE13/00041); and to D.S. (SAF-201342920R, SAF2016-79040-R, and Fondation ACTERIA) with co-funding from the Fondo Europeo de Desarrollo Regional (FEDER). The CNIC is supported by the Ministry of Economy, Industry and Competitiveness (MEIC) and the Pro CNIC Foundation and is a Severo Ochoa Center of Excellence (SEV-2015-0505). S.I. is funded by grant SAF2015-74561-JIN, R.T.-F. by the Fundación Ramón Aréces, V. Z. by ISCIII, and J.-M.G.-G. by the ISCIII Miguel Servet Program and the Instituto de Investigación Sanitaria Hospital 12 de Octubre (imas12).

\section{Author contributions}

R.T.-F., V.Z., S.I., V.R.-P., and J.-M.G.-G. conceived and designed research. R.T.-F., V. Z., and S.I. performed experimental work. G.M.d.H., R.C., B.D., D.S., F.S.-M., and V. A. provided scientific input. D.S., F.S.-M., V.A., and J.-M.G.-G. acquired funding. V. R.-P. and J.-M.G.-G. wrote the manuscript. J.-M.G.-G. supervised the project. All authors revised the manuscript and approved its final version 


\section{Author details}

${ }^{1}$ Centro Nacional de Investigaciones Cardiovasculares Carlos III (CNIC), Madrid, Spain. ${ }^{2}$ Servicio de Inmunología, Hospital de la Princesa, Instituto de Investigación Sanitaria La Princesa (IIS Princesa), Madrid, Spain. ${ }^{3}$ CIBER de Enfermedades Cardiovasculares, Madrid, Spain. ${ }^{4}$ Instituto de Investigación Sanitaria Hospital 12 de Octubre (imas12), Madrid, Spain

\section{Conflict of interest}

The authors declare that they have no competing interests.

\section{Publisher's note}

Springer Nature remains neutral with regard to jurisdictional claims in published maps and institutional affliations.

\section{Supplementary information}

The online version of this article (https://doi.org/10.1038/s41419-017-0007-6) contains supplementary material.

Received: 2 July 2017 Revised: 18 September 2017 Accepted: 19 September 2017

Published online: 08 January 2018

\section{References}

1. Andres, V. \& Gonzalez, J. M. Role of A-type lamins in signaling, transcription, and chromatin organization. J. Cell Biol. 187, 945-957 (2009).

2. Broers, J. L., Ramaekers, F. C., Bonne, G., Yaou, R. B. \& Hutchison, C. J. Nuclear lamins: laminopathies and their role in premature ageing. Physiol. Rev. 86, 967-1008 (2006).

3. Gonzalez-Granado, J. M. et al. Nuclear envelope lamin-A couples actin dynamics with immunological synapse architecture and T cell activation. Sci. Signal. 7, ra37 (2014).

4. Zhu, J., Yamane, H. \& Paul, W. E. Differentiation of effector CD4 T cell populations (*). Annu. Rev. Immunol. 28, 445-489 (2010).

5. Kaech, S. M., Wherry, E. J. \& Ahmed, R. Effector and memory T-cell differentiation: implications for vaccine development. Nat. Rev. Immunol. 2, 251-262 (2002).

6. Szabo, S. J. et al. A novel transcription factor, T-bet, directs Th1 lineage commitment. Cell 100, 655-669 (2000).

7. O'Shea, J. J. \& Paul, W. E. Mechanisms underlying lineage commitment and plasticity of helper CD4+ T cells. Science 327, 1098-1102 (2010).

8. van Panhuys, N., Klauschen, F. \& Germain, R. N. T-cell-receptor-dependent signal intensity dominantly controls CD4(+) $T$ cell polarization in vivo. Immunity 41, 63-74 (2014).

9. Zheng, W. \& Flavell, R. A. The transcription factor GATA-3 is necessary and sufficient for Th2 cytokine gene expression in CD4 T cells. Cell 89, 587-596 (1997).

10. Hale, J. S., Frock, R. L., Mamman, S. A., Fink, P. J. \& Kennedy, B. K. Cell-extrinsic defective lymphocyte development in Lmna(-/-) mice. PLOS ONE 5, e10127 (2010).

11. Swain, S. L., McKinstry, K. K. \& Strutt, T. M. Expanding roles for CD4(+) T cells in immunity to viruses. Nat. Rev. Immunol. 12, 136-148 (2012).

12. Munier, C. M. et al. The primary immune response to Vaccinia virus vaccination includes cells with a distinct cytotoxic effector CD4 T-cell phenotype. Vaccine 34, 5251-5261 (2016).

13. Sen, D., Forrest, L., Kepler, T. B., Parker, I. \& Cahalan, M. D. Selective and sitespecific mobilization of dermal dendritic cells and Langerhans cells by Th1and Th2-polarizing adjuvants. Proc. Natl. Acad. Sci. USA 107, 8334-8339 (2010).

14. Sokol, C. L., Barton, G. M., Farr, A. G. \& Medzhitov, R. A mechanism for the initiation of allergen-induced $\mathrm{T}$ helper type 2 responses. Nat. Immunol. $\mathbf{9}$, 310-318 (2008)

15. Mougneau, E., Bihl, F. \& Glaichenhaus, N. Cell biology and immunology of Leishmania. Immunol. Rev. 240, 286-296 (2011).
16. Sacks, D. \& Noben-Trauth, N. The immunology of susceptibility and resistance to Leishmania major in mice. Nat. Rev. Immunol. 2, 845-858 (2002).

17. Mota, B. E. et al. Adverse events post smallpox-vaccination: insights from tail scarification infection in mice with Vaccinia virus. PLOS ONE 6, e18924 (2011).

18. Qui, H. Z. et al. CD134 plus CD137 dual costimulation induces Eomesodermin in CD4 T cells to program cytotoxic Th1 differentiation. J. Immunol. 187, 3555-3564 (2011)

19. Juno, J. A. et al. Cytotoxic CD4 T cells-friend or foe during viral infection? Front. Immunol. 8, 19 (2017)

20. Iborra, S. et al. H-ras and N-ras are dispensable for T-cell development and activation but critical for protective Th1 immunity. Blood 117, 5102-5111 (2011).

21. Rocha-Perugini, V. \& Gonzalez-Granado, J. M. Nuclear envelope lamin-A as a coordinator of T cell activation. Nucleus 5, 396-401 (2014).

22. Lee, $\mathrm{K}$. et al. Mammalian target of rapamycin protein complex 2 regulates differentiation of Th1 and Th2 cell subsets via distinct signaling pathways. Immunity 32, 743-753 (2010).

23. Lund, E. \& Collas, P. Nuclear lamins: making contacts with promoters. Nucleus 4, 424-430 (2013)

24. Gonzalez, J. M., Navarro-Puche, A., Casar, B., Crespo, P. \& Andres, V. Fast regulation of AP-1 activity through interaction of lamin A/C, ERK1/2, and c-Fos at the nuclear envelope. J. Cell Biol. 183, 653-666 (2008).

25. Ivorra, C. et al. A mechanism of AP-1 suppression through interaction of c-Fos with lamin AVC. Genes Dev. 20, 307-320 (2006).

26. van Panhuys, N. TCR signal strength alters T-DC activation and interaction times and directs the outcome of differentiation. Front. Immunol. 7, 6 (2016).

27. Constant, S. L. \& Bottomly, K. Induction of Th1 and Th2 CD4+ T cell responses: the alternative approaches. Annu. Rev. Immunol. 15, 297-322 (1997).

28. Komai-Koma, M. et al. Interleukin-33 promoting Th1 lymphocyte differentiation dependents on IL-12. Immunobiology 221, 412-417 (2016).

29. Reithinger, R. et al. Cutaneous leishmaniasis. Lancet Infect. Dis. 7, 581-596 (2007).

30. Belkaid, $Y$. et al. CD8+ T cells are required for primary immunity in C57BL/6 mice following low-dose, intradermal challenge with Leishmania major. J. Immunol. 168, 3992-4000 (2002).

31. Uzonna, J. E., Joyce, K. L. \& Scott, P. Low dose Leishmania major promotes a transient $T$ helper cell type 2 response that is down-regulated by interferon gamma-producing CD8+T cells. J. Exp. Med. 199, 1559-1566 (2004).

32. Novais, F. O. et al. Cytotoxic T cells mediate pathology and metastasis in cutaneous leishmaniasis. PLoS Pathog. 9, e1003504 (2013).

33. Scott, P. \& Novais, F. O. Cutaneous leishmaniasis: immune responses in protection and pathogenesis. Nat. Rev. Immunol. 16, 581-592 (2016).

34. Iborra, S. et al. Leishmania uses mincle to target an inhibitory ITAM signaling pathway in dendritic cells that dampens adaptive immunity to infection. Immunity 45, 788-801 (2016).

35. Scott, P., Natovitz, P., Coffman, R. L., Pearce, E. \& Sher, A. Immunoregulation of cutaneous leishmaniasis. $T$ cell lines that transfer protective immunity or exacerbation belong to different $T$ helper subsets and respond to distinct parasite antigens. J. Exp. Med. 168, 1675-1684 (1988)

36. Sullivan, T. et al. Loss of A-type lamin expression compromises nuclear envelope integrity leading to muscular dystrophy. J. Cell Biol. 147, 913-920 (1999).

37. Kim, Y., Zheng, $X$. \& Zheng, $Y$. Proliferation and differentiation of mouse embryonic stem cells lacking all lamins. Cell Res. 23, 1420-1423 (2013).

38. Iborra, S. et al. Optimal generation of tissue-resident but not circulating memory $T$ cells during viral infection requires crosspriming by DNGR-1+ dendritic cells. Immunity 45, 847-860 (2016)

39. Rocha-Perugini, V. et al. CD9 regulates MHC-II trafficking in monocyte-derived dendritic cells. Mol. Cell. Biol. 37, pii: e00202-17 (2017).

40. Melamed, S. et al. Tail scarification with Vaccinia virus Lister as a model for evaluation of smallpox vaccine potency in mice. Vaccine $\mathbf{2 5}$, 7743-7753 (2007).

41. Iborra, S. et al. Vaccination with the Leishmania infantum acidic ribosomal PO protein plus CPG oligodeoxynucleotides induces protection against cutaneous leishmaniasis in C57BL/6 mice but does not prevent progressive disease in BALB/C mice. Infect. Immun. 73, 5842-5852 (2005). 